\title{
LAPAROSCOPIC EVALUATION AND MANAGEMENT OF ADNEXAL PATHOLOGY AMONG WOMEN ATTENDING TERTIARY CARE CENTRE, MAHARASHTRA
}

Milind V. Pawar ${ }^{1}$, Tushar Raghuwanshi², Amol Patil ${ }^{3}$

\section{HOW TO CITE THIS ARTICLE:}

Milind V. Pawar, Tushar Raghuwanshi, Amol Patil. "Laparoscopic Evaluation and Management of Adnexal Pathology among Women Attending Tertiary Care Centre, Maharashtra". Journal of Evolution of Medical and Dental Sciences 2014; Vol. 3, Issue 44, September 15; Page: 10903-10909, D0I: 10.14260/jemds/2014/3423

\begin{abstract}
BACKGROUND: The Laparoscope is a precise diagnostic tool. Laparoscopy represents a considerable advance in the early and accurate diagnosis and management of pelvic pathologic conditions. Laparoscopy now provides the gynecologist valuable information necessary for the choice of treatment in case of adnexal pathology. The present study carried out with the objective to evaluate the role of laparoscopy in diagnosis of adnexal pathology and management of it. METHODOLOGY: The present prospective study carried among women attending outpatient department of gynecology having Adnexal pathology at tertiary care center located in Maharashtra over the period of two years. The data analyzed for frequency distributions showing number and percentages were generated for each identified variables. RESULTS: Total 32 laparoscopies were performed in patients who attended the gynecology department over a period of 2 years. The majority having suspected ectopic pregnancy (37.5\%) \& ovarian cyst (37.5\%).The majority of patients came with history of abdominal pain (62.5\%) and lump in abdomen (21.87\%). Most common laparoscopic procedure carried out for tubal ectopic pregnancies in study was salpingectomy (55.50\%) and Cystectomy (53\%) was done for ovarian mass. Difficulties encountered during laparoscopic procedure were removal of large adnexal masses (3.1\%) and misplaced IUCD (3.1\%).The complication observed was drainage of cyst (6.2\%)during intraoperative while pain in abdomen (25\%), vomiting (9\%) post-operative procedure of laparoscopy. CONCLUSION: The study concludes for evaluation and management of adnexal pathology laparoscopy should be considered the method of choice as it offers the advantages of fewer postoperative adhesions, reduced pain, technically feasible, safe, and better cosmetic results.
\end{abstract}

KEYWORDS: Women, Laparoscopy, Adnexal Pathology, Management.

INTRODUCTION: "Laparoscopy is a most effective technique for bridging the gap between clinical evaluation and major surgical explorations. The Laparoscope is a precise diagnostic tool which should have a much more prominent place in gynecology than it has at the present time with modern optical systems, high intensity fiber optic cold light sources and convenient means of creating and maintaining pneumo peritoneum, the instrument represent as precise, safe and acceptable means of evaluating and managing gynecology patients today.

The evolving laparoscopic technology has enabled endoscopic management of most of adnexal masses ${ }^{1}$. Laparoscopy gives precise information about uterus, fallopian tubes, ovaries and broad ligament structures that cannot be offered by any other clinical examination or investigations. It helps in easier evaluation and management of abdominal pain and pelvic pathology i.e. pelvic masses or adnexal pathology ${ }^{2}$. Laparoscopy helps in successful management of patients with adnexal pathology. 
It provides the gynecologist valuable information necessary for the proper choice of treatment in case of adnexal pathology. The present study carried out with the objective to evaluate the role of laparoscopy in diagnosis of adnexal pathology and management of it.

MATERIAL AND METHODS: The present prospective study carried out in the department of Obstetrics and Gynecology, tertiary care center located in Maharashtra over the period of two years Women of all age group attending Outpatient department of gynecology having Adnexal pathology which includes ectopic pregnancy, ovarian tumor, Tubo-ovarian mass, hydrosalpinx, endometriosis, genital Koch's, ovarian cysts, twisted paratubal cysts, broad ligament fibroid etc. included for study purpose.

Laparoscopy was also performed for evaluation of primary and secondary infertility as well as acute and chronic pelvic pain coming to the department was included for study purpose. Those having suspected genital malignancy and intrauterine pregnancy with adnexal pathology e were excluded from this study. Institutional Ethical Committee approval was taken prior to conducting the study.

All patients were admitted on day prior to the day of laparoscopy except in suspected cases of ruptured ectopic pregnancy and ovarian torsion. Ultrasonography along with routine investigations like complete Haemogram, Blood grouping and Rh typing were done in all cases preoperatively.

The Laparoscopic procedure was performed in a well-equipped operation theatre. General anesthesia was used in all cases. Majority of the patients were discharged on the next day of laparoscopy and were advised to follow up in the outpatient department for assessing the postoperative complications.

The data were entered, cleaned and analyzed in Microsoft ${ }^{\mathrm{TM}}$ Excel ${ }^{\circledR}$ 2007. Frequency distributions showing number and percentages were generated for each identified variables.

OBSERVATION AND RESULTS: Total 32 laparoscopies were performed in patients who attended the gynaecology department over a period of 2 years. Majority of the cases (66\%) were between 21-28 years of age. The youngest was sixteen years of age and oldest was forty two years of age. 31\% patient's nulliparous, $28 \%$ patients' primiparas, $28 \%$ patients para 2 and $12.5 \%$ patients were para 3 or more. The majority of patients were from lower socioeconomic status $(71.9 \%)$ while $9.3 \%$ were seen from upper socioeconomic status.

Figure 1 shows the distribution of the cases studied for laparoscopic evaluation and management of adenexal pathology. Suspected ectopic pregnancy (37.5\%) \& ovarian cyst (37.5\%) were the most common adnexal pathology observed among study cases.

The majority of patients came with history of abdominal pain (62.5\%) and lump in abdomen $(21.87 \%)$. The other symptoms were vaginal bleeding (15.6\%), amenorrhea (15.6\%), vomiting (12.5\%) and syncope (3.12\%).

Table 1 shows Rupture ectopic pregnancy (41.6\%) followed by unrupture pregnancy (33.3\%) were the most common finding in patients with history of acute pain in lower abdomen while Ovarian cyst $(60 \%)$ followed by hydrosaplinx $(10 \%)$ and Tuboovarian mass $(10 \%)$ were laparoscopic finings in chronic lower pain patients.

Distribution of the Tubal and Ovarian pathology after laparoscopic evaluation was shown in Table 2. Tubes were also tested for spillage of dye in 19 cases. Bilateral spillage was observed in 
$53.3 \%$ cases. Most common laparoscopic procedure carried out for tubal ectopic pregnancies was Salpingectomy (55.50\%) and Cystectomy (53\%) for ovarian mass (Table 3). Ectopic pregnancy was with failed puerperal tubal ligation in all cases.

Fig. 2 shows Laparoscopic findings and management of primary infertility patients. One case of primary amenorrhea studied laparoscopic ally shows bilateral streak gonads with absent of uterus. Karyotyping showed Y line. Laparoscopic bilateral Gonadectomy was performed.

Difficulties encountered during laparoscopic procedure were removal of large adnexal masses (3.1\%) and removing misplaced IUCD (3.1\%).IUCD was located in posterior wall of uterus and laparotomy was performed. The complication observed was drainage of cyst $(6.2 \%)$ during intraoperative while pain in abdomen (25\%), vomiting (9\%) post-operative procedure of laparoscopy.

DISCUSSION: Operative laparoscopy is gaining its popularity in the field where laparotomy was routinely done in the past. In our study, total 32 cases were studied for evaluation and management of adnexal pathology.

In the present study, of the twelve-suspected ectopic pregnancies, eight (66\%) were diagnosed on laparoscopy and these patients managed. In one patient (8\%) laparotomy was done due to imperfect homeostasis. In other two patients (16\%), torsion of ovarian cyst was seen and twisted par tubal cyst was observed in one patient:

In present study, early diagnosis and treatment of enraptured ectopic pregnancy (33.3\%) was done laproscopically which is comparable with other studies of Chang et $\mathrm{al}^{3}(42.6 \%)$ as well as Nezhat F et $\mathrm{al}^{4}(30 \%)$. Laparotomy was avoided in $25 \%$ of patients which is similar with other studies. ${ }^{3,4}$ In management of ectopic pregnancy failure rate was seen $12.5 \%$ that was similar with Gajeswska M et al. ${ }^{5}$

During study period, chronic pelvic pain patients had shown ovarian pathology laproscopically. Nine patients $(28.1 \%)$ were of simple ovarian cysts. These finding are more as compared to $18.2 \%$ by Porpora and Gomel $^{6}$ followed by Duignan NM et al $7.66 \%$ and $4.7 \%$ by Shripad Hebbar. ${ }^{8}$

Three patients (9.4\%) were of tubal block. These findings are lesser than Usha Krishna et al ${ }^{9}$ in which tubal block was $17.8 \%$, while Shah P.K. et al10 studied $36.7 \%$. Two cases $(6.25 \%)$ were of adhesions. This result is very much similar with $10.5 \%$ by Patwardhan and Ingle ${ }^{11}$ also $12.05 \%$ by Usha Krishna el $\mathrm{al}^{9}$.One case (3.12\%) showed endometriosis. This result is very much similar i.e.4.7\%.with Shripad Heber ${ }^{8}$. But as much as high incidence (26.4\%) was found to Patwardhan et al. ${ }^{12}$

Low incidence of endometriosis in our series may be due to low socioeconomic condition of patient. Three patients (9.37\%) were of hydrosalpinx. The incidence of hydrosalpinx of our study is very much similar with Nabil El tabbakh ${ }^{13}$ i.e. $8.7 \%$ and Duignan ${ }^{7}$ studied $5.6 \%$ but higher than observed (3.8\%) by Porpora and Gomel. ${ }^{6}$ One case (3.12\%) tuberculosis was mainly in the form of Tuboovarian mass. Rate of tuberculosis in developed countries is very low as compared to developing countries. This is very much similar with Nabil EL Tabbakh ${ }^{13}$ who found $2.01 \%$.

Ovarian cyst of all 15 cases removed laproscopically. In $52.63 \%$ of cases cystectomy was performed while $21.05 \%$ \% 10.5\% cases cyst aspiration and cystectomy \& oophorectomy was performed respectively. These is very much similar with Ki Hyun Park ${ }^{14}$ in which cystectomy in 50\%, 
oophorectomy in $13.5 \%$ and cyst aspiration with cystectomy in $26.9 \%$ and Fanfani ${ }^{15}$ studied cystectomy in $67.9 \%$, oophorectomy in $12 \%$ and cyst aspiration with cystectomy in $21.4 \%$ of cases.

All 3 cases of adnexal torsion were managed laparoscopically including one case of early pregnancy with ovarian torsion without disturbing pregnancy.

In present study, four cases of mature cystic teratomas treated laparoscopically by cystectomy. One case patient had dermoid cyst with early pregnancy, in which MTP with cystectomy was done. In three cases, cysts aspirated and removed with spillage rate of $75 \%$. In one case cyst was removed with colpotomy due to large size. We studied no incidence of chemical peritonitis. All cysts were sent for histopathology. Histopathology of all cysts was mature cystic teratomas (100\%).

In present study, 5 cases of infertility were studied, out of them $4(80 \%)$ were cases of primary infertility $(80 \%)$ and one case of secondary infertility $(20 \%)$ which is very similar i.e. $73.21 \%$ and $75.59 \%$ of primary infertility studied by Shah P.K. et al ${ }^{10}$ and Singh Misra et al ${ }^{16}$ respectively. One case of 16 years girl with primary amenorrhea was treated. On laparoscopy there was absent uterus with streak gonads were seen. On karyotyping, it was 46XY. Laparoscopic bilateral gonadectomy was done. Duignan N. M. et al ${ }^{5}$ observed 3.3\% incidence of gonadal dysgenesis, while Deepa Goal ${ }^{17}$ gives incidence $5.26 \%$ of mullerian agenesis.

Two patients were hydrosalpinx with terminal block treated with cuff salpingostomy laparoscopically. Chromopertubation was done after that and spillage of dye was observed in both cases. In one case pertubal was observed so laparoscopic adhesinolysis was done.

In present study, two cases conversion to laparotomy was done with failure rate of $6.25 \%$. Krishna Usha et al studied 2.2\% per 1000 major complication requiring laparotomise. ${ }^{9}$ No major complication was observed except pain in abdomen (25\%) cases. This observation was similar with other studies. $4,7,9$

In conclusion, laparoscopic approach for managing adnexal pathology should be considered the method of choice as it offers the advantages of fewer postoperative adhesions, reduced pain, technically feasible, safe, and better cosmetic results. The cost and maintenance of the laparoscope though high may overweighed by its advantages. Thus, we conclude that with appropriate evaluation, laparoscopic surgery should replace laparotomy in the management of most adnexal masses.

\section{REFERENCES:}

1. Eli Serur, Pamela L. Emeney, Daniel W. Byrne. Laparoscopic management of adnexal masses. JSLS 2001; 5(2):143-151.

2. Duggal BS et al. Laproscopic management of adnexal masses. MJAFI 2004; 60:28-30.

3. Chang YS, Lee JY, Moon SY, Kim JG. Diagnostic laparoscopy in gynecologic disorders. Asia Oceania J Obstet Gynaecol 1987 Mar; 13 (1): 29-34.

4. Nezhat F, Nezat C, Welander CE. Four ovarian cancers diagnosed during laproscopic management of 1011 women wih adnexal mass. Am J Obstet Gynecol 1992; 167: 790-6.

5. Gajewska $\mathrm{M}$ et al. Laproscopic management of ectopic pregnancy. Neuro Endocrinol Lett. 2008 Apr; 29 (2): 267-71.

6. Parpora MG, Gomel V. Role of Laparoscopy in the management of pelvic pain in women of reproductive age. Fertil Steril 1997; 68 (5):765-79.

7. Duignan NM, Jordan JA Coughlan BM, Logan-Edwards R. One thousand consecutive cases of diagnostic laparoscopy. J Obstet Gynaecol Br Commonw 1972 Nov; 79 (11): 1016-24. 


\section{ORIGINAL ARTICLE}

8. Hebbar S. Role of laparoscopy in chronic pelvic pain. J Min Access Surgery 2005 sep, 96 (6): 491-6.

9. Krishna Usha Sathe A. V. Mehta Hansa. Tubal factors in infertility (Laproscopic study of 679 cases of infertility) J. of Obste Gynec of India.1978.

10. Shah P. K. Batwar O. D. Badhwar V.R. Vaidya P.R. Analysis of tubal factor in 386 cases of Infertility. J of Obstet and Gynecol India 1991; 41: 634.

11. Patwardhan and Ingle A value of laparoscopy in endometriosis as a cause of infertility. J Obstet and Gynecol India 1988; 38: 205.

12. Patwardhan M.V. Damania K.R. Desai S.V. Laprosocpically guided management of pelvic inflammatory diseases. J Obstet and Gynecol India 1988; 21: 326.

13. Adelusi B et al Accuracy of hysterosalpingography and laproscopic hydrotubation in diagnosis of tubal patency. Fertil Steril 1995; 63 (5): 1016-20.

14. Ki Hyun Park. Operative Laparoscopy in treating benign ovarian cyst. Yonsei medical journal 1999; 40 (6): 608-12.

15. Fenfani F. Prospective study of laparoscopy and minlaprotomy in management of benign adnexal masses. Human Reprod 2004; 19 (10): 2367-71.

16. Singh Misra R. Barsia R, Naithan J. A Comparative analysis of diagnostic laparoscopy and HSG in case of infertiliy. J. Obste and Gynecol India 1998; 34: 471.

17. Goel D, R.Prem. Laparoscopy and its gynecological diagnosis. J Obstet and Gynecol India 1991; $41: 373$.

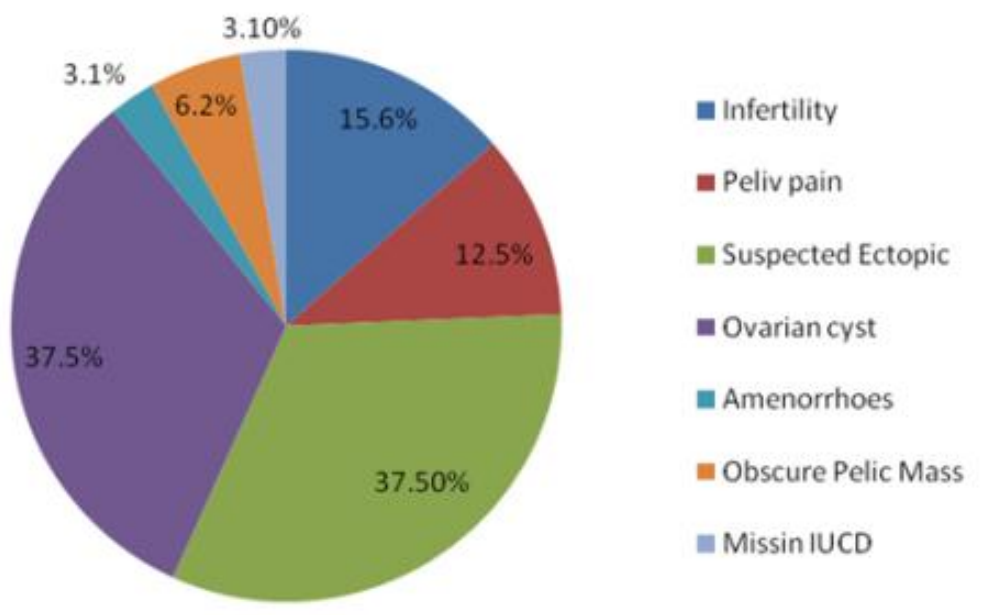

Fig 1: Distribution of Cases for Laproscopic Evaluation and Management of Adnexal Pathology During Study Period.

Fig. 1 


\begin{tabular}{|c|c|c|c|c|}
\hline \multirow{2}{*}{ Sr. No. } & \multicolumn{2}{|c|}{ Acute pain in Lower abdomen } & \multicolumn{2}{c|}{ Chronica pain in lower abdomen } \\
\cline { 2 - 5 } & Laparoscopic Findings & Numbers (\%) & Laparoscopic Findings & Numbers (\%) \\
\hline 01 & Un ruptured Ectopic pregnancy & $4(33.3 \%)$ & ovarian Cyst & $12(60 \%)$ \\
\hline 02 & Ruptured Ectopic pregnancy & $5(41.6 \%)$ & Hydrosalpinx & $02(10 \%)$ \\
\hline 03 & Twisted ovarian Cyst & $2(16.6 \%)$ & Tubo ovarian mass & $02(05 \%)$ \\
\hline 04 & Twisted Para tubal Cyst & $1(8.33 \%)$ & Missing IUCD & $01(05 \%)$ \\
\hline 05 & --- & -- & Streak Gonads & $01(05 \%)$ \\
\hline 06 & --- & -- & Genital Koch's & $01(05 \%)$ \\
\hline 07 & --- & -- & Endometriosis & $01(05 \%)$ \\
\hline
\end{tabular}

Table 1: Laparoscopic finding among cases with history

of acute and chronic pain in lower Abdomen during study period

\begin{tabular}{|c|c|c|c|c|c|c|}
\hline \multirow{2}{*}{$\begin{array}{l}\text { Sr. } \\
\text { no. }\end{array}$} & \multirow{2}{*}{$\begin{array}{c}\text { Ovarian } \\
\text { Pathology }\end{array}$} & Unilateral & Bilateral & \multirow{2}{*}{$\begin{array}{c}\text { Tubal } \\
\text { Pathology }\end{array}$} & Unilateral & Bilateral \\
\hline & & No. (\%) & No. (\%) & & No. (\%) & No.(\%) \\
\hline 1. & Normal & $14(43.8)$ & $10(31.2)$ & Normal & $17(53.1)$ & $12(37.5)$ \\
\hline 2 & Cystic & $01(3.1)$ & $1(3.1)$ & Hydrosalpinx & $3(9.3)$ & $1(3.1)$ \\
\hline 3 & T0 mass & $01(3.1)$ & -- & T0 mass & $2(6.5)$ & -- \\
\hline 4 & Functional cyst & $7(21.8)$ & -- & Tubal block & $3(9.3)$ & $1(3.1)$ \\
\hline 5 & Benign Ovarian Mass & $4(12.5)$ & -- & Ruptured & $5(15.6)$ & -- \\
\hline 6 & Twisted Ovarian Mass & $2(6.2)$ & -- & Thickened & $1(3.1 \%)$ & -- \\
\hline 7 & Endometriosis & $1(3.1)$ & -- & Adhesions & $1(3.1)$ & $2(6.2)$ \\
\hline 8 & Corpus Luteum Cysts & -- & $2(6.2)$ & -- & -- & -- \\
\hline 9 & Streak Gonads & -- & $1(3.1)$ & -- & -- & -- \\
\hline 10 & Pregnancy & $1(3.1)$ & -- & -- & -- & -- \\
\hline
\end{tabular}

\begin{tabular}{|c|c|c|c|c|}
\hline \multirow{2}{*}{$\begin{array}{l}\text { Sr. } \\
\text { No. }\end{array}$} & \multicolumn{4}{|c|}{ Laparoscopic Management } \\
\hline & Ovarian Mass & Numbers (\%) & Tubal Pregnancy & Numbers (\%) \\
\hline 1 & Cystectomy & $10(52.6)$ & Salpingectomy & $03(55.6)$ \\
\hline 2 & Oophorectomy & $02(10.5)$ & Salping-oophorectomy & $01(11.1)$ \\
\hline 3 & Cyst aspiration and Cystectomy & $04(21.0)$ & Salphigostomy & $01(11.1)$ \\
\hline 4 & Detorsion and Cystectomy & $03(15.8)$ & Ovarotomy & $01(11.1)$ \\
\hline 5 & Laparotomy & $00(0)$ & Conversion to laprotomy & $01(11.1)$ \\
\hline 6 & Total & 19 & Total & 07 \\
\hline
\end{tabular}




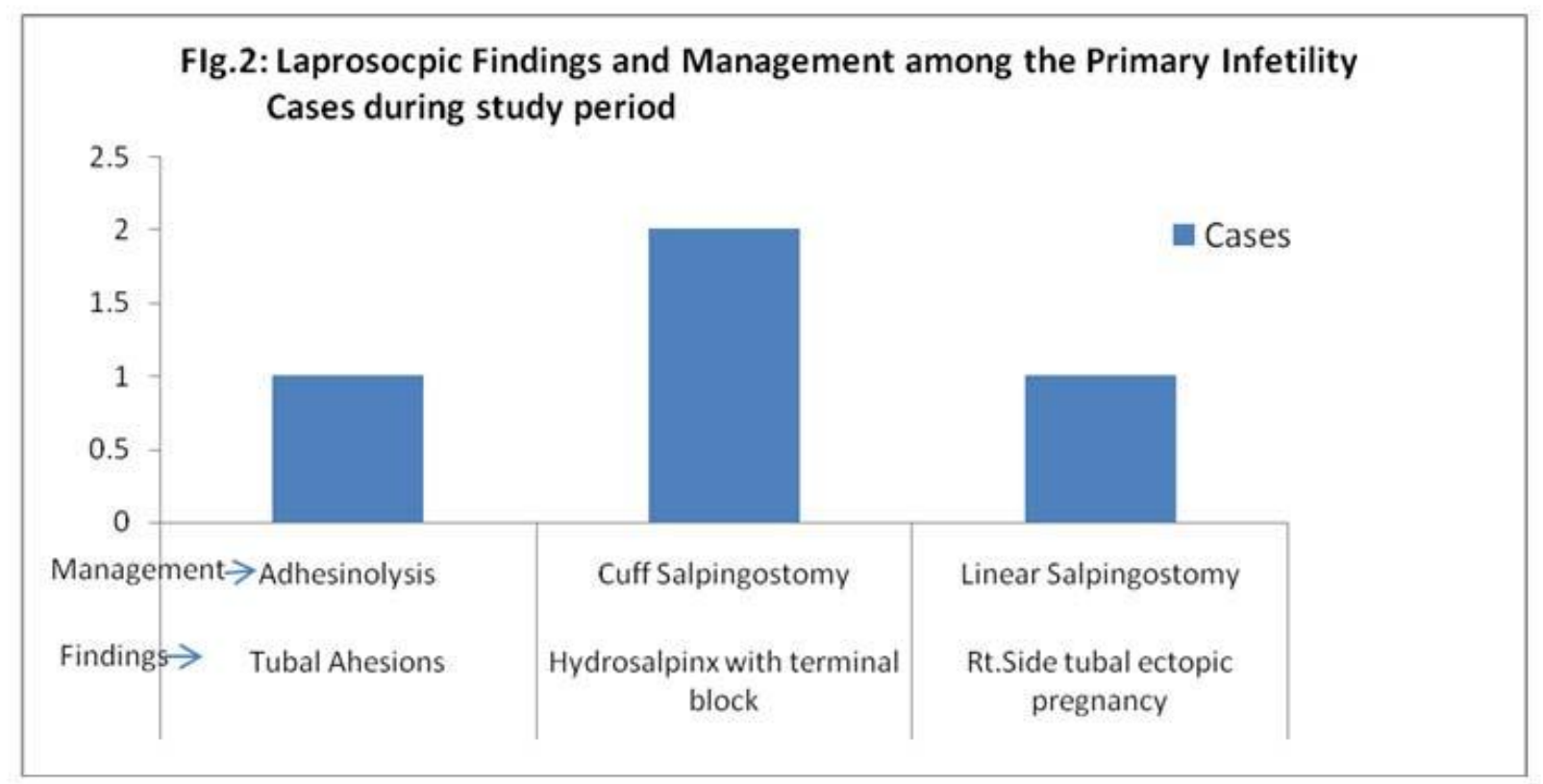

\section{Fig. 2}

\section{AUTHORS:}

1. Milind V. Pawar

2. Tushar Raghuwanshi

3. Amol Patil

\section{PARTICULARS OF CONTRIBUTORS:}

1. Assistant Professor, Department of Obstetrics and Gynaecology, SBH Government Medical College, Dhule.

2. Assistant Professor, Department of Obstetrics and Gynaecology, SBH Government Medical College, Dhule.

3. Assistant Professor, Department of PSM, SBH Government Medical College, Dhule.

\section{NAME ADDRESS EMAIL ID OF THE} CORRESPONDING AUTHOR:

Dr. Milind V. Pawar,

4, Shriram Nagar,

Pawar Wadi,

Dhule-2.

Email: drmilindvpawar@gmail.com

Date of Submission: 03/09/2014.

Date of Peer Review: 04/09/2014.

Date of Acceptance: 09/09/2014.

Date of Publishing: 15/09/2014. 